\title{
АНАЛІЗ ЯКОСТІ ТЕХНІЧНОГО ОБСЛУГОВУВАННЯ ТА РЕМОНТУ ВАГОНІВ І ВПРОВАДЖЕННЯ ГМЕА-МЕТОДОЛОГІЇ НА ПІДПРИЕМСТВАХ ЗАЛІЗНИЧНОЇ ГАЛУЗІ
}

\section{ANALYSIS OF QUALITY OF TECHNICAL SERVICE AND REPAIR OF CARRIAGES AND INTRODUCTION OF FMEA-METHODOLOGY ON THE ENTERPRISES OF RAILWAY INDUSTRY}

\author{
Представив д-р техн. наук, професор І.С. Мартинов
}

Постановка проблеми. Реформування залізниць повинно ініціювати значну кількість інвестиційних проектів і програм у залізничну галузь. Однак відсутність сформованої ринкової інфраструктури та необхідних знань, недостатній досвід роботи в сучасній економіці визначили такі умови й середовище здійснення проектів, при яких різко зросли невизначеність i ризики їx реалізації. Категорії «невизначеність» і «ризик» відіграють велику роль у навколишньому світі. У зв'язку зі специфікою роботи залізничного транспорту ці поняття повинні всебічно вивчатись для недопущення можливості їх виникнення. Із цією метою продовжують упроваджувати на залізничному транспорті України міжнародні стандарти якості.

Актуальність. Державна адміністрація залізничного транспорту України (Укрзалізниця) розглядає можливість впровадження в Україні Міжнародного стандарту IRIS - International Railway Industry Standard [1]. Сфера застосування стандарту - виробництво рухомого складу й комплектуючих. Стандарт задовольняє сучасні вимоги якості обслуговування та ремонту продукції залізничної промисловості, а також враховує ризики та невизначеності, які із цим зв'язані.
Мета статті. Провести аналіз транспортних подій та вплив на них людського фактора. Застосувати методологію FMEA (Failure Modes and Effects Analysis - аналіз причин і наслідків відмов) [2], що подана в новому міжнародному стандарті IRIS 3 метою підвищення надійності і якості продукції залізничного транспорту.

Основна частина. У 2012 році мали місце дев'ять транспортних подій - вісім інцидентів, з них один серйозний, та одне порушення проти 20 (11 інцидентів та дев'ять порушень) у 2011 році (див. табл. 1).

Зростання кількості транспортних подій допущено лише на Придніпровській залізниці з одного до трьох випадків, у т.ч. 3 вини працівників залізниці допущений серйозний інцидент.

При перевірках, проведених фахівцями Головного пасажирського управління, виявлялись випадки незадовільного технічного стану та якості ремонту пасажирських вагонів, а саме: протікання мастила 3 компресора вакуумного туалету на світильники у тамбурі, експлуатація вагона 3 виходом колодки за обід тривалий час; незадовільна очистка рам візків від бруду перед ремонтом; на вагоні випущеному 3 деповського ремонту, пошкоджено 1/3 жил кабелю; порушення кріплення труб. 
Аналіз транспортних подій за 2012 рік

\begin{tabular}{|c|c|c|c|c|c|c|c|c|c|}
\hline \multirow{3}{*}{ Залізниця } & \multicolumn{4}{|c|}{ Інцидент } & \multirow{2}{*}{\multicolumn{2}{|c|}{ Порушення }} & \multirow{2}{*}{\multicolumn{2}{|c|}{$\begin{array}{c}\text { Інциденти та } \\
\text { порушення }\end{array}$}} & \multirow{3}{*}{$+/-$} \\
\hline & \multicolumn{2}{|c|}{ всього } & \multicolumn{2}{|c|}{ У т. ч. серйозні } & & & & & \\
\hline & 2012 & 2011 & 2012 & 2011 & 2012 & 2011 & 2012 & 2011 & \\
\hline Донецька & 1 & 1 & 0 & 0 & 0 & 2 & 1 & 3 & -2 \\
\hline Львівська & 1 & 1 & 0 & 0 & 1 & 2 & 2 & 3 & -1 \\
\hline Одеська & 0 & 5 & 0 & 0 & 0 & 0 & 0 & 5 & -5 \\
\hline Південна & 0 & 1 & 0 & 0 & 0 & 0 & 0 & 1 & -1 \\
\hline Півд.-Західна & 3 & 2 & 0 & 0 & 0 & 5 & 3 & 7 & -4 \\
\hline Придніпровська & 3 & 1 & 1 & 0 & 0 & 0 & 3 & 1 & 2 \\
\hline Разом & 8 & 11 & 1 & 0 & 1 & 9 & 9 & 20 & -11 \\
\hline
\end{tabular}

3 виявлених недоліків бачимо, що технологія ремонту порушується майже у всіх цехах та відділеннях і левову частку недоліків допущено через «людський фактор».
3 метою зниження ризиків, які виникають при технічному обслуговуванні та ремонті вагонів, доцільно впровадження міжнародного стандарту IRIS. Він передбачає проведення FMEA-аналізу, який включає два основних етапи [5], поданих на рисунку.

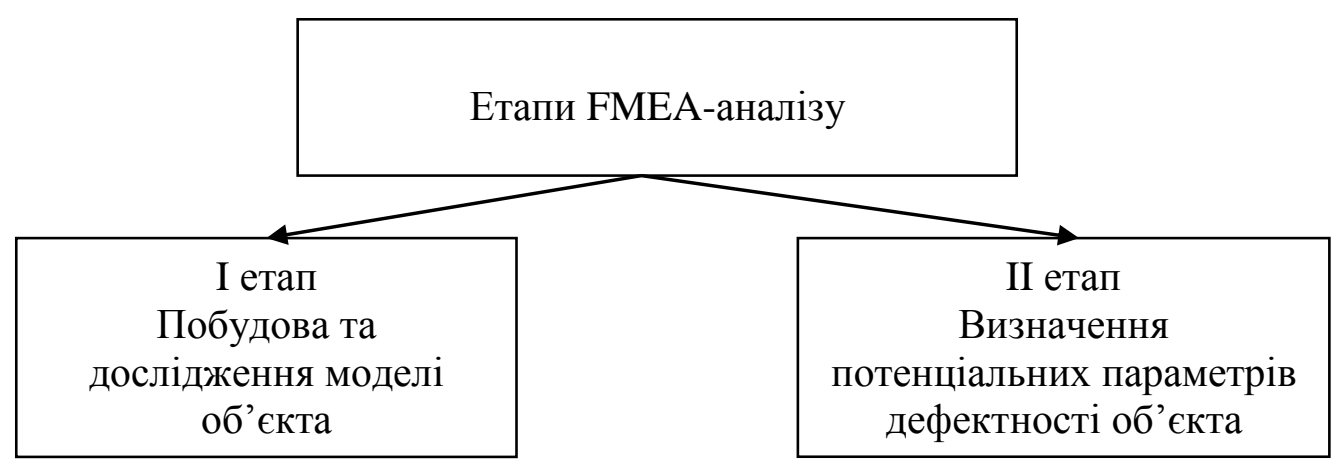

Рис. Схема етапів проведення FMEA-аналізу

I етап включає в себе:

- побудову компонентної, структурної, функціональної й потокової моделей об'єкта аналізу. Якщо FMEA-аналіз проводиться разом із функціональновартісним аналізом (ФВА), то використовуються раніше побудовані моделі. Далі проводиться дослідження моделей.

На II етапі визначаються:

- потенційні дефекти для кожного 3 елементів моделі об'єкта. Такі дефекти звичайно зв'язані або 3 відмовою функціонального елемента (руйнування, відмова), або з неправильним виконанням елементом його корисних функцій;

- потенційні причини дефектів. Для їх виявлення можуть бути використані діаграми Ісікави, які будуються для кожної 3 функцій об'єкта, пов'язаних 3 появою дефекту;

- потенційні наслідки дефектів для споживачів, оскільки кожний з розглянутих 
дефектів може викликати ланцюжок відмов в об'єкті. При аналізі наслідків використовуються структурна й потокова моделі об'єкта;

- можливості контролю появи дефектів. У процесі дослідження визначається, чи може дефект бути виявлений до настання наслідків у результаті передбачених в об'єкті заходів контролю, діагностики, самодіагностики;

- параметр (Е) ваги наслідків для споживача. Це - експертна оцінка, що проставляється за 10-бальною шкалою. Найвищий бал проставляється для випадків, у яких наслідки дефекту спричиняють юридичну відповідальність;

- параметр (А) частоти виникнення дефекту. Це - також експертна оцінка, що проставляється за 10-бальною шкалою. Найвищий бал проставляється, коли оцінка частоти виникнення дефекту становить $25 \%$ і вище;

- параметр (В) імовірності виявлення дефекту. Як і попередні параметри, є 10бальною експертною оцінкою, що відповідає наявності прихованих дефектів, які не можуть бути виявлені до настання наслідків;

- параметр (PRZ) ризику споживача. Він визначається як добуток значень параметрів А, В та Е. Дефекти 3 найбільшим параметром ризику (PRZ $\geq 125$ ) підлягають усуненню в першу чергу. При $\mathrm{RPZ} \leq 60$ коригувальні заходи, як правило, не проводять.

FMEA-аналіз звичайно проводиться в режимі «мозкового штурму» командою фахівців [2]. У роботі [6] проведено дослідження причин виходу 3 ладу колісних пар вагонів. Виконано I та частково II етапи FMEA-аналізу, а саме: на основі статистичних даних побудована діаграма Ісікави та експертним шляхом виявлені першопричини виходу 3 ладу колісних пар.

Аналіз статистичних даних за 20112012 pр. дозволив визначити об'ємний показник якості утримання колісних пар в експлуатації. Розподіл відмов колісних пар в експлуатації наведено у табл. 2.

Побудуємо карту FMEA-аналізу для колісних пар № 436980 та №180971, які вилучені з експлуатації, та подамо ії у табл. 3.

Таблиця 2

Розподіл відмов колісних пар в експлуатації

\begin{tabular}{|l|c|c|c|c|c|c|c|c|c|c|c|c|c|c|}
\hline \multirow{2}{*}{ Несправність } & \multicolumn{2}{|c|}{ Донецька } & \multicolumn{2}{|c|}{ Львівська } & \multicolumn{2}{|c|}{ Одеська } & Південна & \multicolumn{2}{|c|}{ Півд-Зах. Придніпр. } & \multicolumn{2}{|c|}{ Разом } \\
\hline \multicolumn{1}{|c}{} & 2 & 3 & 4 & 5 & 6 & 7 & 8 & 9 & 10 & 11 & 12 & 13 & 14 & 15 \\
\hline Повзун & $\mathbf{2 2}$ & 10 & 0 & 1 & 0 & 3 & 37 & 56 & 24 & 39 & 9 & 15 & 92 & 124 \\
\hline Прокат & $\mathbf{1 0 0}$ & 78 & 55 & 61 & 23 & 24 & 35 & 50 & $\mathbf{2 7}$ & 15 & 2 & 6 & $\mathbf{2 4 2}$ & 234 \\
\hline $\begin{array}{l}\text { Нерівномірний } \\
\text { прокат }\end{array}$ & 1 & 0 & 0 & 0 & 0 & 0 & 4 & 8 & 0 & 4 & 1 & 0 & 6 & 12 \\
\hline Вищербина & $\mathbf{1 6 6}$ & 128 & 18 & 36 & 51 & 58 & 68 & 97 & $\mathbf{1 2 9}$ & 72 & 4 & 9 & $\mathbf{4 3 6}$ & 400 \\
\hline Навар & 1 & 1 & 0 & 0 & 0 & 0 & 0 & 11 & $\mathbf{2 0}$ & 3 & 11 & 30 & 32 & 45 \\
\hline $\begin{array}{l}\text { Кільцевий } \\
\text { виробіток }\end{array}$ & 10 & 23 & $\mathbf{2 9}$ & 23 & 0 & 2 & 0 & 1 & $\mathbf{1 4}$ & 8 & 52 & 54 & 105 & 111 \\
\hline Термотріщини & 13 & 16 & 98 & 99 & 0 & 0 & 0 & 0 & $\mathbf{2 5 6}$ & $\mathbf{2 1 8}$ & 346 & 356 & $\mathbf{7 1 3}$ & 689 \\
\hline $\begin{array}{l}\text { Розшарування } \\
\text { металу }\end{array}$ & 0 & 0 & 22 & 22 & 0 & 0 & 0 & 0 & 0 & 0 & 0 & 0 & 22 & 22 \\
\hline $\begin{array}{l}\text { Гострокінцевий } \\
\text { накат гребеня }\end{array}$ & 3 & 7 & 0 & 0 & 3 & 6 & 12 & 30 & 267 & 409 & 83 & 148 & 368 & 600 \\
\hline Тонкий гребінь & 148 & 151 & 62 & 62 & 35 & 38 & 2 & 2 & $\mathbf{1 0}$ & 0 & $\mathbf{3 2}$ & $\mathbf{2 1}$ & $\mathbf{2 8 9}$ & 274 \\
\hline
\end{tabular}


Продовження табл. 2

\begin{tabular}{|l|c|c|c|c|c|c|c|c|c|c|c|c|c|c|}
\hline \multicolumn{1}{|c|}{1} & 2 & 3 & 4 & 5 & 6 & 7 & 8 & 9 & & & 10 & 11 & 12 & 13 \\
\hline $\begin{array}{l}\text { Різниця тов- } \\
\text { щин гребенів }\end{array}$ & $\mathbf{1 4 1}$ & 125 & $\mathbf{1 5 0}$ & 136 & 45 & 55 & 49 & 91 & 102 & 102 & 56 & 99 & 543 & 608 \\
\hline $\begin{array}{l}\text { Уширення } \\
\text { ободу }\end{array}$ & 49 & 95 & 1 & 3 & 6 & 7 & 4 & 21 & $\mathbf{1 3}$ & 12 & 21 & 31 & 94 & 169 \\
\hline Тонкий обід & 1 & 1 & $\mathbf{1 3}$ & 0 & 0 & 0 & $\mathbf{6}$ & 2 & 0 & 0 & 0 & 0 & $\mathbf{2 0}$ & 3 \\
\hline $\begin{array}{l}\text { Круговий } \\
\text { наплив металу }\end{array}$ & $\mathbf{7}$ & 4 & 0 & 0 & 0 & 0 & 0 & 1 & 4 & 7 & 15 & 22 & 26 & 34 \\
\hline $\begin{array}{l}\text { Викид мастила } \\
\text { через лабіринт }\end{array}$ & 0 & 1 & 0 & 0 & 0 & 0 & 0 & 0 & 0 & 0 & 1 & 0 & 1 & 1 \\
\hline $\begin{array}{l}\text { Обводнення } \\
\text { мастила }\end{array}$ & 1 & 2 & 0 & 0 & 0 & 0 & 0 & 0 & 0 & 0 & 1 & 0 & 2 & 2 \\
\hline $\begin{array}{l}\text { Послаблення } \\
\text { торцевого } \\
\text { кріплення }\end{array}$ & 1 & 8 & 0 & 0 & 0 & 0 & 0 & 0 & 0 & 0 & 0 & 1 & 1 & 9 \\
\hline Перекіс букси & 0 & 0 & 0 & 0 & 0 & 0 & 0 & 0 & 0 & 0 & 1 & 2 & $\mathbf{1}$ & 2 \\
\hline $\begin{array}{l}\text { Вертикальний } \\
\text { підріз гребеня }\end{array}$ & 0 & 0 & 4 & 0 & 0 & 0 & 0 & 0 & 0 & 0 & 0 & 0 & 4 & 0 \\
\hline $\begin{array}{l}\text { Несправність } \\
\text { підшипників }\end{array}$ & $\mathbf{2 1}$ & 18 & 8 & 238 & 0 & 0 & 0 & 0 & 0 & 0 & 0 & 0 & $\mathbf{2 9}$ & 256 \\
\hline $\begin{array}{l}\text { Тріщина } \\
\text { корпусу букси }\end{array}$ & 0 & 2 & 0 & 0 & 0 & 0 & 0 & 0 & 0 & 0 & 0 & 0 & 0 & 2 \\
\hline $\begin{array}{l}\text { Несправність } \\
\text { редуктора }\end{array}$ & 28 & 29 & 4 & 23 & 2 & 0 & 0 & 0 & 4 & 4 & 0 & 0 & 38 & 56 \\
\hline $\begin{array}{l}\text { Різиця } \\
\text { діаметрів } \\
\text { колісної пари }\end{array}$ & $\mathbf{1 1 4}$ & 102 & 176 & 226 & 0 & 0 & 0 & 0 & 0 & 0 & 0 & 1 & 290 & 329 \\
\hline \begin{tabular}{l} 
ВСьОГО \\
\hline
\end{tabular} & $\mathbf{8 2 7}$ & 801 & 640 & 930 & 165 & 193 & 217 & 370 & 870 & 893 & 635 & 795 & 3354 & 398 \\
\hline
\end{tabular}

Таблиця 3

Карта FMEA-аналізу колісних пар вагона

\begin{tabular}{|c|c|c|c|c|}
\hline & $\begin{array}{c}\text { Потенційний } \\
\text { дефект }\end{array}$ & $\begin{array}{c}\text { Потенційні } \\
\text { причини }\end{array}$ & $\begin{array}{c}\text { Потенційні } \\
\text { наслідки }\end{array}$ & Вид контролю \\
\hline Вузол & $\mathrm{A}$ & $\mathrm{B}$ & $E$ & RPZ \\
\hline \multirow[t]{2}{*}{$\begin{array}{c}\text { Колісна } \\
\text { пара } \\
\text { № } 436980\end{array}$} & Термотріщина & $\begin{array}{l}\text { Порушення } \\
\text { технології } \\
\text { виготовлення }\end{array}$ & $\begin{array}{l}\text { Дефекти на } \\
\text { поверхні } \\
\text { кочення, вихід } \\
\text { з ладу }\end{array}$ & $\begin{array}{l}\text { Руйнівний } \\
\text { контроль }\end{array}$ \\
\hline & 8 & 3 & 6 & 144 \\
\hline \multirow[t]{2}{*}{$\begin{array}{c}\text { Колісна } \\
\text { пара } \\
\text { №180971 }\end{array}$} & $\begin{array}{l}\text { Нерівномір-ний } \\
\text { прокат }\end{array}$ & $\begin{array}{l}\text { Порушення } \\
\text { технології } \\
\text { формування } \\
\text { колісних пар }\end{array}$ & $\begin{array}{l}\text { Передчасний } \\
\text { вихід } 3 \text { ладу }\end{array}$ & Діагностика \\
\hline & 2 & 4 & 5 & 40 \\
\hline
\end{tabular}


Виходячи 3 табл. 3, коригувальні заходи щодо результатів аналізу доцільно проводити в такій послідовності:

- виключити причину виникнення дефекту в результаті слідування технології виготовлення коліс для зменшення можливості виникнення дефекту (зменшити параметр А);

- перешкодити виникненню дефекту за рахунок статистичного регулювання (зменшити параметр А);

- знизити вплив дефекту (зменшити параметр Е). Мається на увазі, що вихід 3 ладу колісної пари, що експлуатується, може привести до аварій та катастроф;

- полегшити й підвищити вірогідність виявлення дефекту (зменшити параметр В) за рахунок чіткого дотримання технологічного процесу виготовлення колеса.

Висновки. Систематичне застосування методології FMEA дозволить підвищити якість продукції та послуг на залізничному транспорті та окупиться завдяки таким перевагам: знижується ймовірність повторних або нових відхилень за рахунок цілеспрямованого аналізу всіх критичних невідповідностей; методичні вимоги системного й повного обліку потенційних проблем запобігають появі відхилень при створенні нових конструкцій і технологій; скорочуються витрати засобів i часу на наступні зміни виробів, а також підвищення витрат на випробування за рахунок запобігання появі відхилень на стадії розробки й планування.

\section{Список літератури}

1. Dr. David Scrimshire. IRIS - Global business management system for the railway industry supply chain // Technical Paper. - December, 2006.

2. Анализ видов и последствий потенциальных отказов. FMEA: справочное руководство. Крайслер корпорейшн, Дженерал Моторс корпорейшн. [Текст]: пер. с англ. Н.Новгород: АО «НИЦ КД», СМЦ «Приоритет», 1997.-67с.

3. Дотянуться до стандарта [Текст] // Сириус. Транспортное обозрение. - 2007. №11. - С. 46-50.

4. ISO 9001:2001. Quality management systems - Reguirements (Системи управління якістю - Вимоги).

5. Розно, М.И. Как научиться смотреть вперед? Внедрение FMEA - методологии. Методы менеджмента качества [Текст] / М.И. Розно. - 2000. - № 6.

6. Ніколаєнко, А.О. Удосконалення нормативної бази для вхідного контролю колісних пар вагонів [Текст]: дис. ... канд. техн. наук / А.О. Ніколаєнко. - Севастополь, 2008. - 151 с.

Ключові слова: вагон, технічне обслуговування, ризик, статистичні методи контролю, якість, безпека, надійність.

\section{Анотації}

У статті розглянута методологія FMEA (Failure Modes and Effects Analysis - аналіз причин і наслідків відмов), що подана в новому міжнародному стандарті залізничної промисловості IRIS.

Проведено FMEA-аналіз, побудована карта FMEA-аналізу колісних пар вагонів, а також визначені потенціальні параметри дефектності даних об’єктів.

Зроблено висновок, що систематичне застосування методології FMEA дозволить підвищити якість продукції та послуг на залізничному транспорті та окупиться завдяки: зниженню ймовірності повторних або нових відхилень за рахунок цілеспрямованого аналізу 
всіх критичних невідповідностей об'єкта; статистичному обліку ряду проблем, що дозволить уникнути помилок або повторних робіт.

В статье рассмотрена методология FMEA (Failure Modes and Effects Analysis - анализ причин и следствий отказов), которая представлена в новом международном стандарте железнодорожной промышленности IRIS.

Проведен FMEA-анализ, построена карта FMEA-анализа колесных пар вагона, а также определены потенциальные параметры дефектности данных объектов.

Сделан вывод, что систематическое применение методологии FMEA позволит повысить качество продукции и услуг на железнодорожном транспорте и окупится благодаря: снижению вероятности повторных или новых отклонений за счет целенаправленного анализа всех критических несоответствий объекта; статистическому учету ряда проблем, который позволит избежать ошибок или повторных работ.

In the article considered methodology FMEA (Failure Modes and Effects Analysis - an analysis of the reasons and effect refusal) that is presented in new international standard of railway industry IRIS.

Organized FMEA-analysis, is built card FMEA-analysis wheel pair of the coach, as well as are determined potential parameters defect given object.

It Is Made conclusion that systematic using to methodologies FMEA will allow to raise the quality to product and services on rail-freight traffics and is dipped due to: reduction to probability repeated or new deflections to account of the goal-directed analysis all critical discrepancy object; the statistical account of the row of the problems, which will allow to avoid the mistake or repeated work. 